\title{
Impacto de la pandemia de la COVID-19 en la cantidad de publicaciones
}

\author{
Impact of the COVID-19 pandemic on the amount of \\ publications
}

Portiansky, Enrique Leo; Moré, Gastón; García-Mitacek, Carla; Idiart, Julio Roberto; Metz, Germán2; Galosi, Cecilia Mónica

\section{Enrique Leo Portiansky}

Director de Analecta Veterinaria, Argentina

Gastón Moré

Consejo editorial de Analecta Veterinaria, Argentina

Carla García-Mitacek

Consejo editorial de Analecta Veterinaria, Argentina

Julio Roberto Idiart

Consejo editorial de Analecta Veterinaria, Argentina

Germán Metz

Consejo editorial de Analecta Veterinaria, Argentina

\section{Cecilia Mónica Galosi}

Consejo editorial de Analecta Veterinaria, Argentina

\author{
ANALECTA VETERINARIA \\ Universidad Nacional de La Plata, \\ Argentina ISSN: 1514-2590 \\ Periodicidad:Semestral \\ vol. 41, núm. 1, e054, 2021 \\ analecta@fcv.unlp.edu.ar
}

\section{URL: http://portal.amelica.org/ameli/jatsRepo/25/251984002/ index.html}

DOI: https://doi.org/10.24215/15142590e054

En nuestra nota editorial del primer semestre del año 2020 (Portiansky, 2020) hacíamos referencia a la reducción de las prácticas profesionales, tanto fuera como dentro de los laboratorios de nuestro país y del mundo, por causa de la pandemia de la COVID-19. En vista a ello, especulábamos acerca del caudal de material a ser publicado en los siguientes meses. La hipótesis indicaba que la mayoría de los trabajos no relacionados con diferentes aspectos del nuevo coronavirus sería el producto de experimentos realizados con anterioridad a la fecha del cierre de los establecimientos educativos y de investigación. Hoy nos encontramos a más de un año de aquella fecha inicial, en marzo de 2020, y vemos las consecuencias de lo mencionado: los trabajos presentados por los diferentes investigadores han disminuido, tanto en nuestra revista, como en muchas otras de nuestro país y del mundo. 


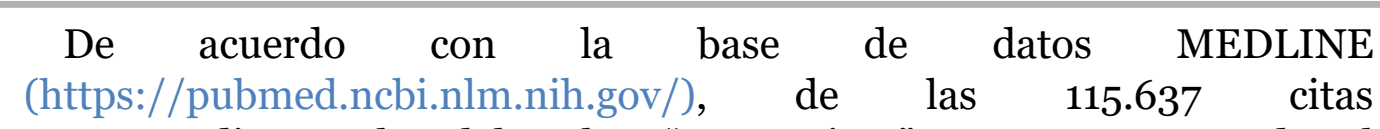
correspondientes a la palabra clave "coronavirus", 109.127 corresponden al bienio 2020-2021. Es decir, en el último año y medio se publicó el 94,3\% del material acerca del virus y de los alcances de la infección. De esas cifras, 9732 trabajos referidos a animales no humanos fueron publicados entre 1949 y 2019, mientras que en los últimos 2 años se publicaron 4301 trabajos $(44,2 \%)$ que, en su mayoría, probablemente correspondan a animales de experimentación. Sin embargo, para otros temas, la producción científica no reflejó los mismos índices. Si por ejemplo tomamos como palabras clave "mastitis bovina", en el año 2020 se publicaron 271 artículos, mientras que en el año anterior (2019) se habían publicado 340. En el primer semestre del año 2020, se habían publicado 173 de los 271 (63,8\%). Durante el primer semestre de este año 2021, solo se publicaron 58 trabajos en el tema. De la misma manera, se pueden realizar búsquedas de palabras clave generales acerca de procesos infecciosos, de producción o experimentación con animales y en la mayoría de los casos se va a observar un patrón similar, debido a que muchas experiencias iniciadas debieron ser suspendidas o retrasadas por las medidas sanitarias vigentes.

No solo el cierre de los centros de investigación ha impactado negativamente en el caudal de publicaciones. Se le suma también el incremento del precio de los insumos, reactivos y equipamiento de investigación a nivel mundial, que repercute particularmente en nuestro país, donde los subsidios para la investigación no solo no se actualizan, sino quesufren retrasos de desembolso.

Lentamente, los distintos países irán restableciendo las actividades experimentales a medida que la vacunación de la población permita retomar las actividades cotidianas. De esa manera, aquellas revistas que usualmente contamos con un número acotado de trabajos científicos iremos incrementando nuestro caudal de información para los más diversos lectores, hasta alcanzar nuestros valores históricos. Será un proceso paulatino, pero ANALECTA VETERINARIA estará abierta, como desde hace más de 115 años, a todos aquellos que quieran publicar en una revista de alcance nacional y americano en temas que hacen al saber científico en el área de las ciencias veterinarias.

\section{Referencias}

Portiansky EL. ANALECTA VETERINARIA en tiempos de pandemia. Analecta Veterinaria.40:1. 2020. http://doi.org/10.24215/15142590e043 